\title{
Application of lean manufacturing technology in a milk manufacturing company
}

\author{
Morakinyo Kehinde Onifade ${ }^{1}$, Olufemi Adebayo Oroye ${ }^{2 *}$ \\ ${ }^{1}$ Department of Mechanical Engineering, Bells University of Technology, Benja village 112104, Ota, Nigeria \\ ${ }^{2}$ Department of Management Technology, Bells University of Technology, Benja village 112104, Ota, Nigeria
}

\begin{tabular}{l} 
ARTICLE INFORMATION \\
\hline Article history: \\
Received: September 3, 2021 \\
Revised: November 6, 2021 \\
Accepted: November 26, 2021 \\
\hline Keywords: \\
Lean manufacturing \\
Time series analysis \\
Linear transfer function \\
Econometric linear transfer function
\end{tabular}

*Corresponding Author

Oroye Olufemi Adebayo

E-mail: oaoroye@bellsuniversity.edu.ng

\section{A B S T R A C T}

\begin{abstract}
This work presents the application of lean management principle in the area of waste elimination in a powder milk plant of a production company. The existing manufacturing procedure for the company's plant was evaluated, and a lean manufacturing technique was developed for the plant. To achieve this, a time series analysis was carried out on the econometric data obtained, and a future forecast predicting losses and usage was predicted based on the practised manufacturing procedures. The econometric linear transfer function technique applied to the actual usage and actual loss data obtained filtered the waste in the production process and generated forecast values for actual loss and usage. This revealed that there had been poor manufacturing practices in the factory. The findings from this research can be used as a guide to managers on wastage control in a production system.
\end{abstract}

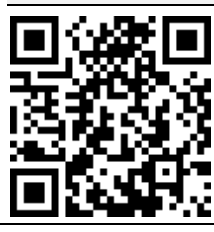

This is an open-access article under the CC-BY-NC-SA license.

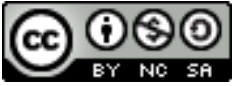

() 2021 Some rights reserved

\section{INTRODUCTION}

The ever re-occurring global economic crisis usually led to collapse in the production system of industries and they eventually affect the demand for goods and services from consumers [1], [2]. This crisis led to industries struggling for survival by cutting down on expenses that affected quality (in some cases) and some shutting down facilities while others merged. However, Anthony [3] argued that period as such should be an opportunity for industries to reengineer and tailor operation towards lean production to reduce waste and avoidable expenses across the production stages while quality is enforced all through the production stages.
Also, Most companies nowadays, due to many competitors in the market, are forced to adopt tools and techniques in production of goods to promote cost reduction with quality being maintained to remain sustainable and meet raising demands [4]. Lean management principles and techniques ensure an efficient production mechanism for any firm to remain sustainable without compromising quality. As introduced in the Toyota production system, the concept of lean manufacturing is to improve quality delivery and production process optimization via the reduction in both waste generation and inventory [5]. According to Dudbridge [6], lean is that meat part that is fat-free (i.e. principally consisting of lean 
muscle) hence, lean thinking aims at reduction of wastes (fats) that are detrimental and of a burden on any system. Lean as Lean Enterprise, Lean Management or Manufacturing (LM), Lean Production, and defines it as sets of principles, tools and techniques implemented by companies/organizations to heighten their efficiency in production by aiming at waste reduction in adding values to customers [7]. In another perspective lean manufacturing aim at having same output with lesser input; these inputs include less cost, less human effort, less machinery, less material, less space and less time [6]. Lean can be defined as a systematic approach used in waste identification and elimination by combining sets of tools and techniques utilized in continuous improvement on product and service firms rendered. The importance of having a manufacturing system based on lean manufacturing is enormous, including quality improvement in the production system, waste elimination in the production system, and production cost reduction, which directly affects societal prosperity [1], [8].

In as much as lean principle has a positive influence on any company's effectiveness, efficiency that brings about an increase in productivity, value addition and at the same time, reduction in waste, not all of the principles are applicable to all industries; hence, the need to first analyze and measure its essentials [9], [10]. Some organizations/companies have failed to implement lean practices due to a lack of understanding and performance measures, hence, the need for quantitative models [11] to appraise lean performance, its effectiveness on the production system and seek areas for potential improvements decision-makers of the organization.

The concept of lean thinking can be categorized into value identification, waste elimination, and Flow Generation [12]. This concept of lean thinking leads to the five key principles of lean manufacturing as reported by El Faydy \& El Abbadi [13], which are the elimination of waste; identification of the value stream; achievement of flow through the process; pacing by a pull signal, and continuous pursuit of perfection.

Of all these five principles, eliminating waste is the focus of this research whose case study is a milk manufacturing company in Nigeria. In industry, waste is referred to as anything that adds no value to the end product of manufactured goods [14]. This industrial waste is of two types:
Seen/Calculated Waste and Unseen / Uncalculated Waste. The Seen/Calculated Waste includes breakdown and defects, while Unseen/Uncalculated Waste includes waste due to improper transportation of materials and men and an improper working environment. However, these types of industrial waste are embedded in the three types of waste identified by the lean concept, which are: Mura (Unevenness), Muri (Overburden) and Muda (activities that have no value addition to customers). This type of waste can also be divided into seven types: overproduction, inventory, extra processing steps, motion, defects, waiting, and transportation [15]. In agreement with in order to align with the objectives of the lean practice, the milk production company identifies the need to reduce waste generation to the highest possible level in pursuit of satisfying their customers demand and optimizing the company's losses [16], [17].

The powder factory at the Milk Company understudied is in a batch production establishment. The existing production methods have resulted in certain levels of profits and losses over the period being studied. This research understudied these outputs in relation to the concerned inputs to develop a lean manufacturing practice for this powder factory.

\section{RESEARCH METHODS}

This research was conducted based on secondary data obtained from the company. A monthly record of actual usage of raw materials, actual loss of raw materials and the associated monetary loss for five (5) years was developed into a time series data of sixty (60) months. The research project employed econometric models in evaluating the data obtained from existing methods of production. This econometric model consists of some input processes, which are autoregressive (AR) and moving average (MA). The hybrid of these two-time series processes formulates the linear transfer function as expressed in equations (1) and (2). The MA process was carried out on the actual usage data (xt), while the AR process was carried out on the actual loss data $y_{t}$. The actual loss data had a sinusoidal pattern that encircled the abscissa, while the actual usage data had an increasing pattern.

$Y_{t}=V_{1}(B) X_{t}+u_{1 t}$ 


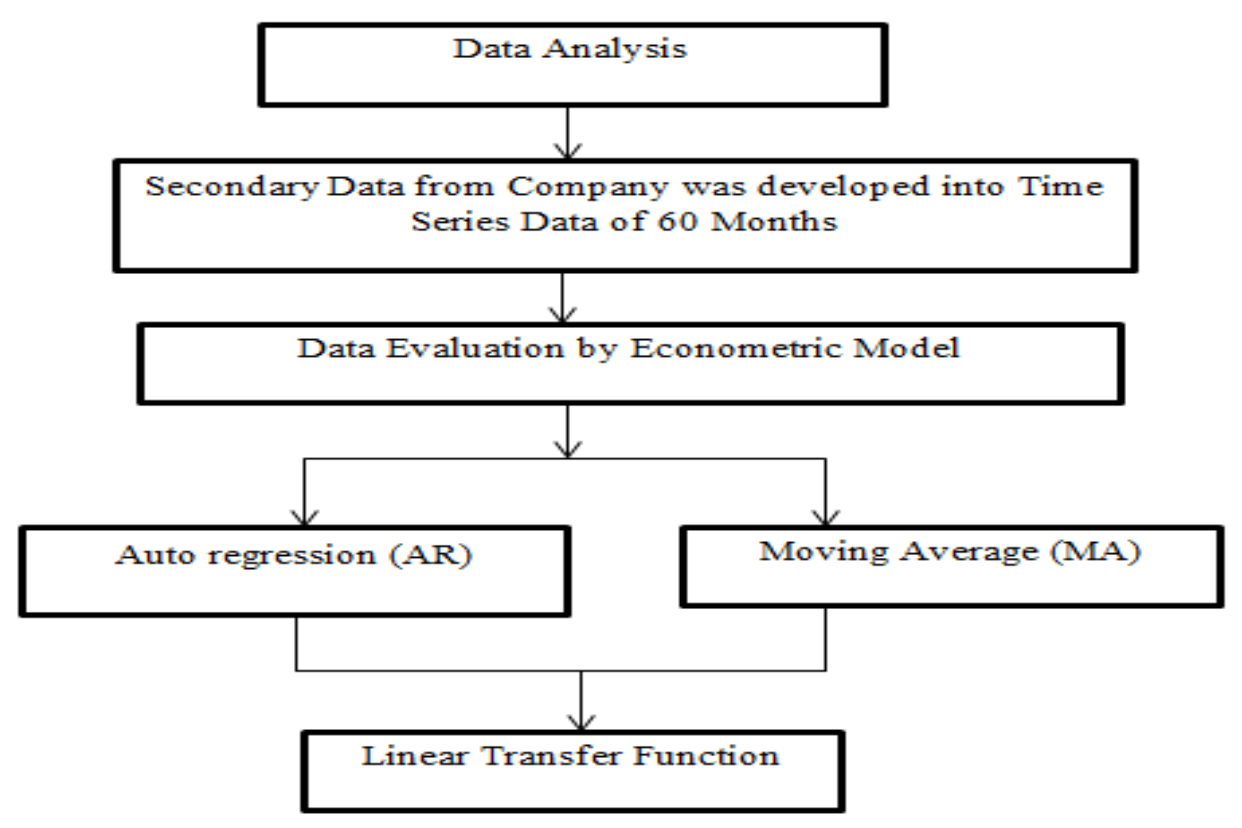

Fig. 1. Flowchart of research methods

$X_{t}=V_{2}(B) Y_{t}+u_{2 t}$

Where $\mathrm{t}=1,2, \ldots \ldots, \mathrm{n}$ and

$V_{1}(B)=v_{1} B+v_{2} B^{2}+\cdots+v_{s} B^{S}$

$V_{2}(B)=\omega_{1} B+\omega_{2} B^{2}+\cdots+\omega_{\theta} B^{\theta}$

The auto-regression analysis was carried out on the actual loss data. The functional analysis for this auto regression modelling was the computation of autocorrelation function (ACF), usually represented as $r_{k}$, which was carried out by taking three or four lags on the time series. $r_{k}$ for each lag was computed based on the formula for $r_{k}$ given as $r_{k}=\frac{\sum(\mathrm{y}-\overline{\mathrm{y}})\left(\mathrm{y}_{\mathrm{t}-\mathrm{k}}-\overline{\mathrm{y}}\right)}{\sum\left(\mathrm{y}_{\mathrm{t}}-\overline{\mathrm{y}}\right)^{2}}$. The best three lags are rated as the best candidate for the autoregression analysis. The second, third and fourth lags were selected and used for the autoregression (AR) analysis.

The moving average analysis was carried out on the actual usage data in which its model was analyzed through the computation of the autocorrelation function (ACF). The ACF computation took three or four lags on the time series and computed the $r_{k}$ for each lag. The best three lags are rated as the best candidate for the moving average analysis. The formula for $r_{k}$ is given as $\mathrm{r}_{\mathrm{k}}=\frac{\sum(\mathrm{x}-\overline{\mathrm{x}})\left(\mathrm{x}_{\mathrm{t}-\mathrm{k}}-\overline{\mathrm{x}}\right)}{\sum\left(\mathrm{x}_{\mathrm{t}}-\overline{\mathrm{x}}\right)^{2}}$.

The second, third and fourth lags were selected and used for the moving average (MA) analysis. Also, multivariate analysis was performed on the actual loss, actual usage and the monetary loss, in which the monetary loss was the response variable for the multivariate analysis. The research flow diagrammatic illustration is as shown in Fig. 1.

\section{RESULTS AND DISCUSSION}

From the results of the research conducted, the following conditions were obtained. The summing variables for the AR process were used to develop a set of normal equations as shown in equations (5) to (8). these normal equations were represented in canonical form as shown in equations (9) to (11).

$293725=60 \beta 0+285465 \beta 1+283195 \beta 2+281807 \beta 3$

$940535327=285465 \beta 0+6360716901 \beta 1+2569017347 \beta 2+$

$925740015 \beta 3$

$1884227816=283195 \beta 0+2569017347 \beta 1+6355564001 \beta 2$

$+2565866587 \beta 3$

$975933821=281807 \beta 0+925740015 \beta 1+2565866587 \beta 2+$ $281807 \beta 3$

$A=\left(\begin{array}{c}293725 \\ 940535327 \\ 1884227816 \\ 975933821\end{array}\right)$

$B=\left(\begin{array}{l}\beta_{0} \\ \beta_{1} \\ \beta_{2} \\ \beta_{3}\end{array}\right)$

$C=\left(\begin{array}{cccc}60 & 285465 & 283195 & 281807 \\ 285465 & 6360716901 & 2569017347 & 925740015 \\ 283195 & 2569017347 & 6355564001 & 2565866587 \\ 281807 & 925740015 & 2565866587 & 281807\end{array}\right)$

The regression parameters associated with 
these normal equations were determined by equation 12.

$B=\operatorname{inv} C * A$

Represented in vector form as shown in equation (9) to (11), with $\beta_{0}=-1042.46781766808$, $\beta_{1}=-0.15377430226, \beta_{2}=0.55023095656$, $\beta_{3}=0.86707425476$ Thus, the developed AR model for the actual loss data is shown in equation (13).

$\tilde{y}=-1042.47-0.15377 y_{t-2}+0.55023 y_{t-3}+$ $0.86707 y_{t-4}$

The developed auto regression model is shown in equation (13) was used to predict both in-sample and out-of-sample forecasts. The in-sample predictions using the AR model are shown in Table 1, while the out-of-sample forecast is shown in Table 2.

Table 1. In-sample prediction using the AR model developed

\begin{tabular}{ccrcr}
\hline $\mathbf{T}$ & $\begin{array}{c}\text { Actual } \\
\left(\mathbf{y}_{\mathbf{t}}\right)\end{array}$ & $\begin{array}{c}\text { Forecast } \\
\left(\boldsymbol{y}_{\boldsymbol{t}}\right)\end{array}$ & Error & $\mathbf{e}^{\wedge} \mathbf{2}$ \\
\hline 55 & 3,296 & 3326.84537 & -31 & 951.4368504369 \\
56 & $-6,613$ & 3213.29137 & $-9,826$ & $96,556,002.088137$ \\
57 & 1,388 & 4717.26865 & $-3,329$ & $11,084,029.743873$ \\
58 & 2,270 & 6257.71494 & $-3,988$ & $15,901,870.442699$ \\
59 & 4,484 & -2036.71103 & 6,521 & $42,519,672.336764$ \\
60 & 3,776 & -6361.74257 & 10,138 & $102,773,824.41559$ \\
\hline
\end{tabular}

Table 2. Out-of-sample prediction using the AR model.

\begin{tabular}{lc}
\hline $\mathbf{T}$ & Forecast $\left(\widetilde{\boldsymbol{y}}_{\boldsymbol{t}}\right)$ \\
\hline 61 & 720.54058 \\
62 & 2812.3747 \\
\hline
\end{tabular}

The in-sample AR forecast with the least associated error is $\hat{y}_{t}=55$. This was used to determine the linear transfer function parameter because it has the lowest in-sample forecast residual. The AR model could predict two-step out-of-sample values. These values were used as input for the econometric LTF future forecast model. The summing variables for the MA process were used to develop a set of normal equations as shown in equations (14) to (17). Likewise, the normal equations were represented in canonical form as shown in equations (18) to (20).

$146588158=60 \beta_{0}+140500671 \beta_{1}+136623205 \beta_{2}$ $+132994737 \beta 3$
$354586958467409 \beta_{2}+348099813194622 \beta_{3}$

$361175824689160=136623205 \beta_{0}+354586958467409 \beta_{1}+$ $354718248870727 \beta_{2}+340517697165321 \beta_{3}$ $353738008680098=132994737 \beta_{0} \quad+348099813194622 \beta_{1}+$ $34517697165321 \beta_{2}+341552468843703 \beta_{3}$

$A=\left(\begin{array}{c}146588158 \\ 370935846555212 \\ 361175824689160 \\ 353738008680098\end{array}\right)$

$B=\left(\begin{array}{l}\beta_{0} \\ \beta_{1} \\ \beta_{2} \\ \beta_{3}\end{array}\right)$

$C=$
60
$\left(\begin{array}{cc}140500671 & 369752991451883 \\ 136623205 & 354586958467409 \\ 132994737 & 348099813194622\end{array}\right.$

136623205 354586958467409 35471824880727

132994737 348099813194622 340517697165321

The process parameters associated with these normal equations were obtained via equation (12), using MATLAB software and are as follows: $\beta_{0}=823214.886180650, \quad \beta_{1}=$ $0.426269183, \beta_{2}=-0.006499655$, and $\beta_{3}=$ 0.287170479 . Thus the developed MA model for the actual usage data is shown in equation (20). The developed moving average model is shown in equation (21) was used to predict both in-sample and out-of-sample forecasts. The in-sample predictions using the MA model are shown in Table 3, while the out-of-sample forecast is shown in Table 4.

$\ddot{x}=823214.886+0.426269 \mathrm{x}_{\mathrm{t}-2}-0.0064997 \mathrm{xt}_{\mathrm{t}-3}+0.28717 \mathrm{xt}_{\mathrm{t}-4}$

Table 3. In-sample prediction using the MA model developed

\begin{tabular}{cccrc}
\hline $\mathbf{T}$ & $\begin{array}{c}\text { Actual } \\
(\mathbf{X t})\end{array}$ & $\begin{array}{c}\text { Forecast } \\
\left(\tilde{\boldsymbol{x}}_{\boldsymbol{t}}\right)\end{array}$ & \multicolumn{1}{c}{ Error } & $\mathbf{e}^{\wedge} \mathbf{2}$ \\
\hline 55 & 2957342 & 3465731.63 & -508390 & 58460014025 \\
56 & 3861317 & 3299340.96 & 561976 & 15817075139 \\
57 & 3628468 & 3086957.85 & 541510 & 93233247468 \\
58 & 3877466 & 3545557.74 & 331908 & 10163093118 \\
59 & 3084324 & 3194080.82 & -109757 & 12046557764 \\
60 & 3003163 & 3561328.89 & -558166 & 31154916051 \\
\hline
\end{tabular}

Table 4. Out-of-sample prediction using the MA model.

\begin{tabular}{cc}
\hline $\mathbf{T}$ & Forecast $\left(\tilde{\boldsymbol{x}}_{\boldsymbol{t}}\right)$ \\
\hline 61 & 3154751.383 \\
62 & 3196814.905 \\
\hline
\end{tabular}

The in-sample MA forecast with the least associated error is $\hat{x}_{t}=59$. This was used for the determination of the linear transfer function 
parameter because it has the lowest in-sample forecast residual. The MA model could predict two-step out-of-sample values. These values were also used as input for the econometric LTF future forecast model.

\subsection{Backshift operator for linear transfer function}

The backshift operator for both AR process and MA process was obtained using the following formula: Backshift operator for y (loss) series is $B_{x}=\frac{Y_{i-1}}{Y_{i}}$

and that of actual usage ( $\mathrm{x}$ series) is

$B_{y}=\frac{X_{i-1}}{X_{i}}$

This form part of the inputs for the classical econometric linear transfer function model for the actual and loss data as shown in equations (24) and (25).

$y_{t}=V_{1}\left(B_{y}\right) x_{t}$

$x_{t}=V_{1}\left(B_{x}\right) y_{t}$

$\mathrm{V} 1$ and V2 are the linear transfer components associated with the various backshift operators.
The computations of the components of equations (24 and 25) are carried out using Microsoft Excel software as shown in Appendix 1.

\subsection{Determination of linear transfer function components (LTF)}

The AR component of the LTF is expressed as follow. $A R=V_{1}\left(B_{y}\right) x_{t}$. The forecast value of $\mathrm{AR}$ at $\mathrm{t}=55, \mathrm{y}_{\mathrm{t}=55}=3326.85$. The backshift operator at $\mathrm{t}=55, \mathrm{~B}_{\mathrm{y}} \mathrm{x}_{\mathrm{t}=55}=4625333.134$. Then $V_{1}=\frac{A R_{55}}{B_{Y} x_{t}}=$ 0.00071926 . For the MA components of the LTF, forecast value at $\mathrm{t}=59$ was used. Where $\mathrm{Xt}_{=59}=$ 3196814.91 and $\mathrm{B}_{\mathrm{x}} \mathrm{y}_{\mathrm{t}}=5637.072352$,

$V_{2}=\frac{M A_{59}}{B_{x} Y_{t}}=566.62$

\subsection{Classical econometric linear transfer function model evaluation (ELTF)}

The developed econometric linear transfer function model is of the form shown in equations (26) and (27).

$\mathrm{Y}_{\mathrm{t}}=0.00071926 \mathrm{~B}_{\mathrm{y}} \mathrm{X}_{\mathrm{t}}$

$\mathrm{X}_{\mathrm{t}}=566.62 \mathrm{~B}_{\mathrm{x}} \mathrm{y}_{\mathrm{t}}$

Table 5. Out-of-sample computations for the backshift operators

\begin{tabular}{ccccccc}
\hline Months & $\begin{array}{c}\text { Actual } \\
\text { usage }\end{array}$ & $\begin{array}{c}\text { Backshift } \\
\text { operator }\end{array}$ & Loss & \multicolumn{3}{c}{ Backshift operator } \\
\hline T & $\mathbf{X}$ & $\mathbf{B x}$ & $\mathbf{Y}$ & $\mathbf{B y}$ & $\mathbf{B y x t}$ & $\mathbf{B x Y t}$ \\
\hline 61 & 3154751.383 & 0.951949183 & 720.54058 & 5.240509841 & 16532505.67 & 685.9180161 \\
62 & 3196814.905 & 0.986842053 & 2812.3747 & 0.25620362 & 819035.5524 & 2775.369622 \\
\hline
\end{tabular}

Table 6. Out-of-sample computations for the backshift operators

\begin{tabular}{lrrlllr}
\hline $\mathbf{T}(\mathbf{s})$ & \multicolumn{1}{c}{$\mathbf{B}_{\mathbf{y}} \mathbf{x}_{\mathbf{t}}$} & $\mathbf{B}_{\mathbf{x}} \mathbf{y}_{\mathbf{t}}$ & $\mathbf{V}_{\mathbf{1}}$ & $\mathbf{V}_{\mathbf{2}}$ & $\mathbf{Y}_{\mathbf{t}}$ & \multicolumn{1}{c}{$\mathbf{X}_{\mathbf{t}}$} \\
\hline 10 & 403190.036 & 1116.34 & 0.000719267 & 566.62 & 2899.93 & 632540.00 \\
20 & 4524407.227 & 227.36 & 0.000719267 & 566.62 & 3254.26 & 128823.89 \\
30 & 6358903.248 & -2600.56 & 0.000719267 & 566.62 & 4573.75 & -1473529.31 \\
40 & 919.76786 & -88466390.61 & 0.000719267 & 566.62 & -63630.96 & 521158.87 \\
50 & 34392289.311 & 24575.08 & 0.000719267 & 566.62 & 2473.77 & 13924730.70 \\
60 & 3566257.063 & 3878.05 & 0.000719267 & 566.62 & 2565.09 & 2197378.99 \\
\hline
\end{tabular}

Table 7. In-sample econometric LTF evaluation

\begin{tabular}{llccc}
\hline T & Actual usage, $\mathbf{Y}$ & Actual loss, $\mathbf{X}$ & ELTF usage $\mathbf{X}_{\mathbf{t}}$ & ${\text { ELTF loss } \mathbf{Y}_{\mathbf{t}}}$ \\
\hline 10 & 2236369 & 1202 & 632540.00 & 2899.93 \\
20 & 1951443 & 292 & 128823.89 & 3254.26 \\
30 & 2367885 & -2782 & -1473529.31 & 4573.75 \\
40 & 2960672 & 862 & 521158.87 & -63630.96 \\
50 & 3302996 & 24186 & 13924730.70 & 2473.77 \\
60 & 3003163 & 3776 & 2197378.99 & 2565.09 \\
\hline
\end{tabular}


Where the $\mathrm{B}_{\mathrm{y}} \mathrm{x}_{\mathrm{t}}$ and $\mathrm{B}_{\mathrm{x}} \mathrm{y}_{\mathrm{t}}$ are the out-of-sample backshift operators, the out-of-sample forecast values for $\mathrm{AR}(\mathrm{yt})$ and $\mathrm{MA}\left(\mathrm{x}_{\mathrm{t}}\right)$ were used to compute the forecast values for $\mathrm{B}_{\mathrm{y}} \mathrm{x}_{\mathrm{t}}$ and $\mathrm{B}_{\mathrm{x}} \mathrm{y}_{\mathrm{t}}$, as shown in Table 5. These out-of-sample AR and MA values were used to run the backshift for two subsequent months subsequent ( $\mathrm{t}=61$ and $\mathrm{t}=62$ ). Therefore, the Econometric Linear Transfer Function (ELTF) in-sample evaluations are as computed in Table 6. Hence, the In-sample econometric LTF evaluation is summarized in Table 7. The out-of-sample evaluation of the econometric data was carried out as shown respectively:

$$
\begin{array}{rl}
\mathrm{Y}=61 & 0.000719267 \times 16532505.67 \\
& =11891.28575574389 \\
\mathrm{Xt}=61 & =566.629 \times 685.9180161 \\
& =388661.0395447269 \\
\mathrm{Yt}=62 & =0.000719267 \times 819035.55 \\
& =589.10524294185 \\
\mathrm{Xt}=62 & =566.629 \times 2775.37 \\
& =1572605.12773
\end{array}
$$

\subsection{Multivariate analysis of the econometric data}

The multivariate analysis of the econometric data was carried out as shown in the follow equation:

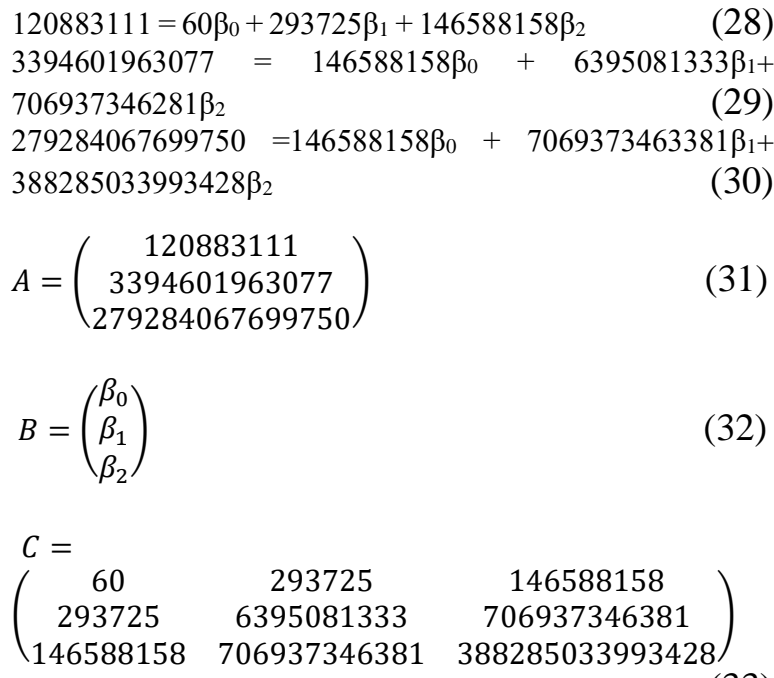

The multivariate model for the econometric data will now be written as follow:

$\hat{y}=62494.78+564.93 X_{1}-0.3324 X_{2}$

where $\hat{y}=$ monetary loss, $X_{1}=$ actual loss and $X_{2}=$ actual usage.

The adjusted coefficient of determination was determined using equation (35) [18].

$\overline{R^{2}}=1-\frac{\Sigma^{\left(y_{t}-\hat{y}\right)^{2}} /(n-k)}{\Sigma^{\left(y_{t}-\bar{y}\right)^{2} / n-1}}=0.999996$

where $\mathrm{k}=$ number of parameters, $\mathrm{n}=$ number of dependent variables, $\hat{y}$ is the predicted value, $\mathrm{y}_{\mathrm{t}}$ is the actual value and $\bar{y}$ is the average value. The $R^{2}$ is very high, suggesting a good fit for the data. This means the estimated regression line fit the data very well. The result compare well with literature values such in some cases [19], [20].

\subsection{Results of moving average (MA) computation}

The data obtained for the actual record of milk powder factory usage or for a period of sixty (60) months is presented graphically in Fig. 2. The plot shows an upward trend and cyclical pattern which suggested that this actual usage did not follow a predetermined and controlled process. Moving average process was carried out and the results showed that the forecast value at $t=59$ has the least associated error. The plot of the actual and predicted moving average (MA) is shown in Fig. 3.

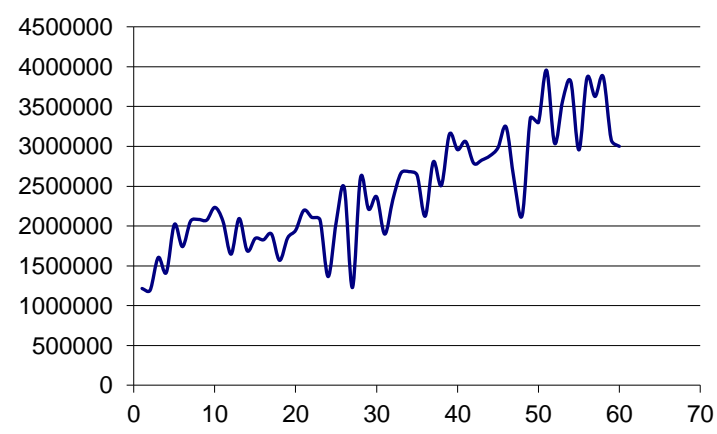

Fig. 2. Plot of actual usage of powder for sixty months

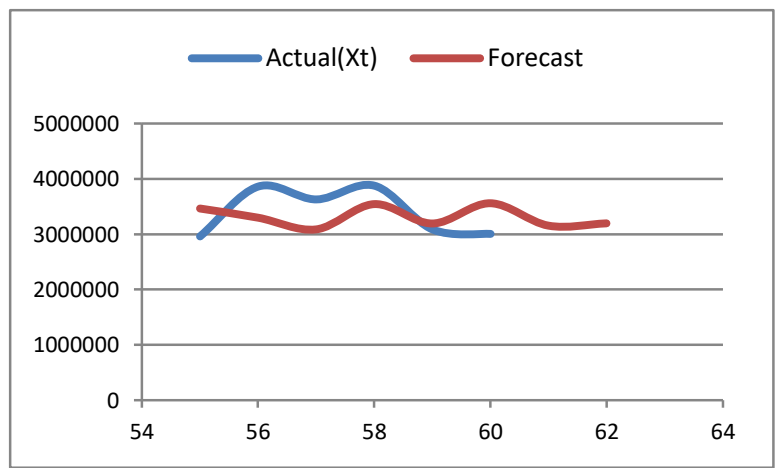

Fig. 3. Plot of actual usage and predicted MA usage 


\subsection{Results of autoregression computation}

The data obtained for the actual record of milk powder factory losses for a period of sixty (60) months is presented graphically in Fig. 4. The plot shows no upward trend but cyclical pattern which suggested that these actual losses followed a predetermined and controlled process. Also, the auto regression (AR) process was carried out and the results shown in Fig. 5 implies that the forecast value at $\mathrm{t}=55$ has the least associated error.

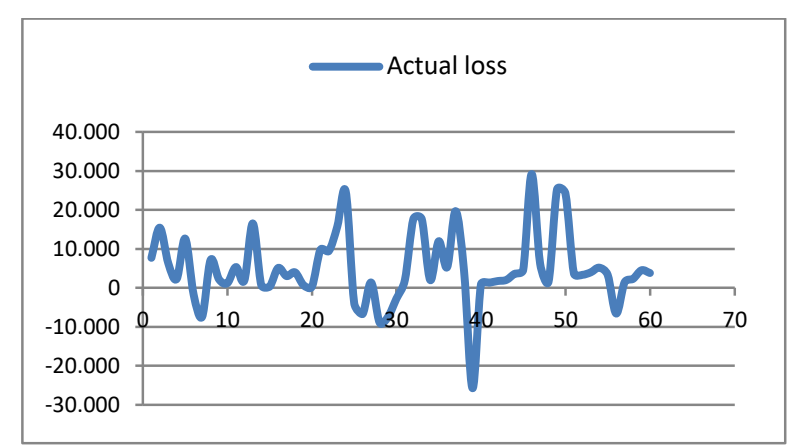

Fig. 4. Plot of actual powder loss for sixty months

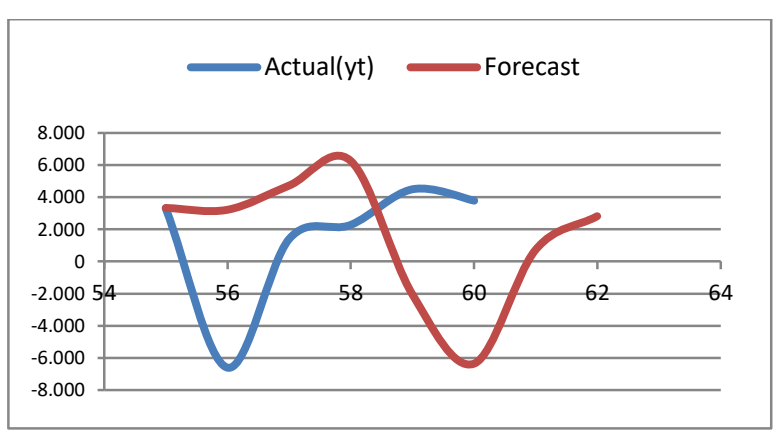

Fig. 5. Plot of actual loss and predicted AR losses

\subsection{Results of the econometric forecast}

The econometric linear transfer function modelling results revealed that the values for the actual loss declared in the company's records are low compared with the ELTF modelled values. It is evident in Fig. 3 that in the thirtieth month $(\mathrm{t}=30)$, the negative loss value was declared, which indicated profit was modelled as a loss value. Also, in the fortieth month ( $t=40)$, the actual loss value was modelled as a profit. The graphical representation of the actual losses and the ELTF losses are shown in Fig. 6.

The econometric linear transfer function modelling results revealed that the values for the actual usage declared in the company's records are so low compared with the ELTF modelled values.
It is evident that in the thirtieth month $(\mathrm{t}=30)$, the negative modelled value obtained against the positive usage value also supported that the negative loss declared for that month was actually supposed to be positive (Fig. 7).

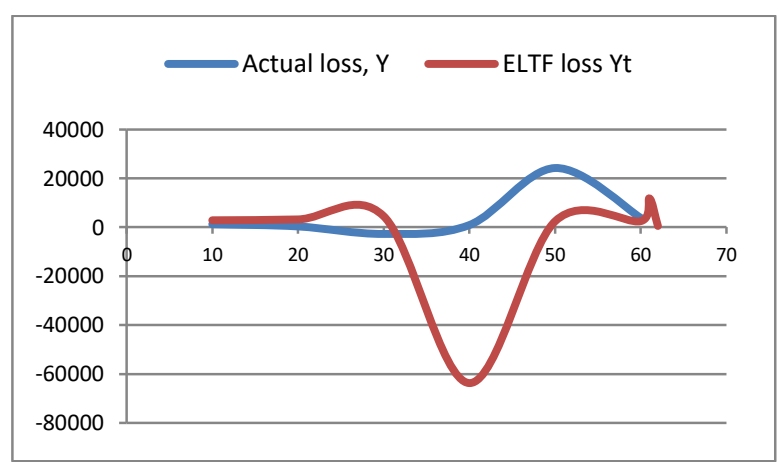

Fig. 6. Plot of actual loss and ELTF loss

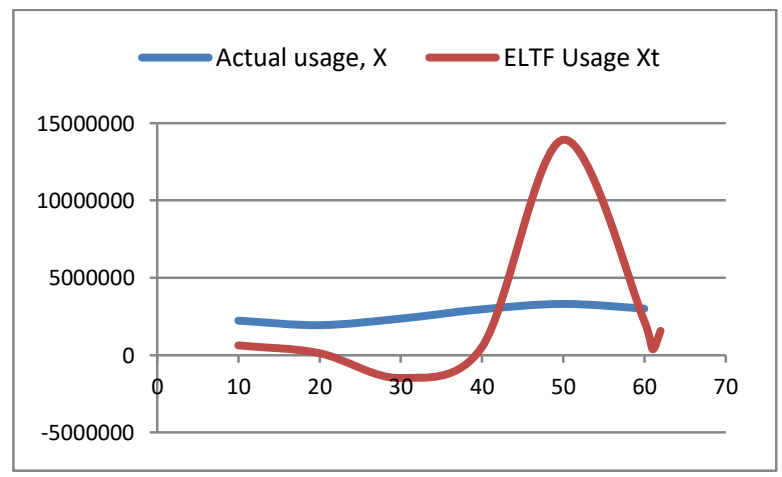

Fig. 7. Plot of actual usage and ELTF usage

The plot of monetary loss/profit is shown in Fig. 8. The plot shows a cyclical pattern which suggests that these actual losses followed a predetermined and controlled process. The multivariate analysis showed that the monetary loss is dependent on the actual loss and actual usage. A large monetary loss was recorded with a very small value of actual usage.

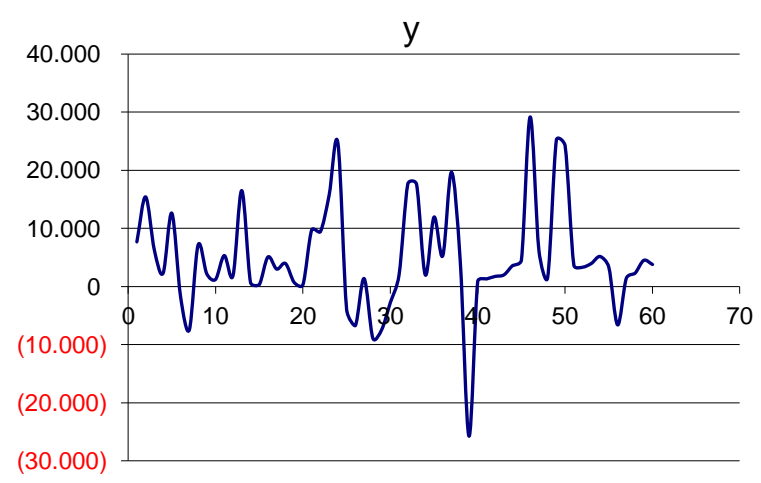

Fig. 8. Plot of monetary loss/profit for sixty months 


\section{CONCLUSION}

The econometric linear transfer function model developed from the data obtained revealed that the present manufacturing practices at the powder factory had numerous associated losses of materials. The recorded values for actual usage of materials comprised of the waste incurred during the production process. The ELTF model operates a feedback system between the actual usage and actual loss, enabling it to predict the systemized values of losses and materials usage. The ELTF modelled values are based on lean manufacturing principles. This is because the modelled system evaluated the losses and usage based on the presented records and generated modelled values which were based on the interaction between the two factors. The feedback process filtered out the wastage in the production system, and the actual usage values of lean production were generated. The associated losses that the factory's conventional practices incurred on powder materials, based on the ELTF model, were also generated. The values are model-based, and these could have their associated errors. The results of the multi variance analysis carried out on the monetary loss showed that a very small fraction of the actual usage had an effect on the factory profitability. This supports the fact already established that the majority of the actual usage recorded were wastages in one form or the other.

The underlining principle of lean technology is the elimination of waste in manufacturing processes. The econometric linear transfer function technique applied to the actual usage and actual loss data obtained filtered the waste in the production process and generated forecast values for actual loss and usage. This revealed, probably, that there had been poor manufacturing practices in the factory. The research findings could be used to control future wastage in the production system.

\section{REFERENCES}

[1] K. Mitrogogos and K. M. Saidul Huq, "Impact of Lean Manufacturing on Process Industries," $2018 . \quad$ Available: http://bth.diva-

portal.org/smash/record.jsf?pid=diva2\%3 A1221378\&dswid=-321

[2] W. Beacham, "Ten years on from the financial crisis," 2017. Available: https://www.icis.com/explore/resources/n ews/2017/08/10/10132891/ten-years-onfrom-the-financialcrisis/.
[3] P. Anthony, "Lean in a Lean Economy," 2017. Available: https://retailandhospitalityhub.com/manuf acturing/manufacturing-industryupdates/lean-in-a-lean-economy/.

[4] P. Moser, O. Isaksson, and R. Seifert, "How process industries can improve supply chain performance," CSCMP's Supply Chain Q., vol. 3, no. 3, 2017. Available: http://www.divaportal.org/smash/record.jsf?pid=diva2\%3 A1 154173\&dswid=-7633

[5] J. P. Womack and D. T. Jones, "Lean Thinking-Banish Waste and Create Wealth in your Corporation," J. Oper. Res. Soc., vol. 48, no. 11, pp. 1148-1148, Nov. 1997, doi: 10.1057/palgrave.jors.2600967.

[6] M. Dudbridge, Handbook of Lean Manufacturing in the Food Industry. Wiley, 2011. Available: https://books.google.co.id/books?id=iF2sSNHvbsC

[7] F. Mwacharo, "Challenges of Lean Management: Investigating the challenges and developing a recommendation for implementing Lean management techniques," Hämeen ammattikorkeakoulu, 2013. Available: https://www.theseus.fi/bitstream/handle/1 0024/58871/Mwacharo_Fiona.pdf

[8] T. Melton, "The Benefits of Lean Manufacturing: What Lean Thinking has to Offer the Process Industries," Chem. Eng. Res. Des., vol. 83, no. 6, pp. 662-673, 2005, doi: 10.1205/cherd.04351.

[9] L. F. Romero and A. Arce, "Applying Value Stream Mapping in Manufacturing: A Systematic Literature Review," IFACPapersOnLine, vol. 50, no. 1, pp. 10751086, 2017, doi: 10.1016/j.ifacol.2017.08.385.

[10] R. Sundar, A. N. Balaji, and R. M. S. Kumar, "A Review on Lean Manufacturing Implementation Techniques," Procedia Eng., vol. 97, pp. 1875-1885, 2014, doi: 10.1016/j.proeng.2014.12.341.

[11] F. Behrouzi and K. Y. Wong, "Lean performance evaluation of manufacturing systems: A dynamic and innovative approach," Procedia Comput. Sci., vol. 3, pp. 388-395, 2011, doi: 10.1016/j.procs.2010.12.065. 
[12] A. Droste, "Lean thinking, banish waste and create wealth in your corporation," Action Learn. Res. Pract., vol. 4, no. 1, pp. 105-106, Apr. 2007, doi: 10.1080/14767330701233988.

[13] N. El Faydy and L. El Abbadi, "Overview of Lean-Green Approach," in Proceedings of the 2nd African International Conference on Industrial Engineering and Operations Management, 2020, pp. 1-8. Available:

http://www.ieomsociety.org/harare2020/p apers/97.pdf.

[14] A. Dixit, V. Dave, and A. P. Singh, "Lean manufacturing: An approach for waste elimination," Int. J. Eng. Res. Technol., vol. 4, no. 4, pp. 532-536, 2015. Available: https://www.ijert.org/research/leanmanufacturing-an-approach-for-wasteelimination-IJERTV4IS040817.pdf.

[15] W. W. Chandra and S. Noya, "Waste Analysis in Self-Service Process," J. Ilm. Tek. Ind., vol. 2, no. 3, pp. 168 - 173, 2014. Available:

http://journal.tarumanagara.ac.id/index.ph $\mathrm{p} / \mathrm{jidtind} /$ article/view/1671.

[16] R. Shah and P. T. Ward, "Defining and developing measures of lean production,"
J. Oper. Manag., vol. 25, no. 4, pp. 785805, Jun. 2007, doi: 10.1016/j.jom.2007.01.019.

[17] A. Pal and S. S. Kachhwaha, "Waste cooking oil: a promising feedstock for biodiesel production through power ultrasound and hydrodynamic cavitation," J. Sci. Ind. Res., vol. 72, no. 6, pp. 387392, $2013 . \quad$ Available: http://nopr.niscair.res.in/handle/12345678 9/18679.

[18] R. Bartels, "Re-interpreting R2, regression through the origin, and weighted least squares," Univ. Sydney Bus. Sch., 2015. Available:

https://www.researchgate.net/profile/Robe rt-Bartels/publication/283333191.

[19] Z. Hossain, M. Ishaq Bhatti, and Z. Ali, "An econometric analysis of some major manufacturing industries," Manag. Audit. J., vol. 19, no. 6, pp. 790-795, Jan. 2004, doi: 10.1108/02686900410543895.

[20] A. Heshmati and M. Ncube, "An econometric model of employment in Zimbabwe's manufacturing industries," $J$. Dev. Econ, vol. 17, no. 3, pp. 527-551, 1998. Available: http://jed.or.kr/fulltext/29-2/Almas_Heshamati.pdf. 


\section{APPENDIX}

Appendix 1. Computations of the components of the classical econometric models

\begin{tabular}{|c|c|c|c|c|c|c|}
\hline \multirow{2}{*}{$\begin{array}{l}\text { Months } \\
\text { T }\end{array}$} & \multirow{2}{*}{$\begin{array}{c}\text { Actual } \\
\text { usage } \\
X^{-}\end{array}$} & \multirow{2}{*}{$\begin{array}{c}\begin{array}{c}\text { Backshift } \\
\text { operator } \\
\text { Bx }\end{array} \\
\end{array}$} & \multirow[t]{2}{*}{ Loss } & \multicolumn{3}{|c|}{ Backshift operator } \\
\hline & & & & By & Byxt & BxYt \\
\hline 1 & 1218236 & - & 7,668 & - & - & - \\
\hline 2 & 1196386 & 1.018263336 & 15,407 & 0.497695853 & 595436.3502 & 15688.38322 \\
\hline 3 & 1607255 & 0.744366015 & 6,255 & 2.46314948 & 3958909.318 & 4656.009426 \\
\hline 4 & 1418981 & 1.132682538 & 2,278 & 2.745829675 & 3896280.138 & 2580.250821 \\
\hline 5 & 2023204 & 0.701353398 & 12,599 & 0.180808001 & 365811.4701 & 8836.35146 \\
\hline 6 & 1743550 & 1.16039345 & $(1,772)$ & -7.110045147 & -12396719.22 & -2056.217194 \\
\hline 7 & 2063445 & 0.844970426 & $(7,462)$ & 0.237469847 & 490005.9689 & -6305.169316 \\
\hline 8 & 2084695 & 0.989806662 & 7,097 & -1.051430182 & -2191911.243 & 7024.657883 \\
\hline 9 & 2076993 & 1.003708246 & 2,167 & 3.27503461 & 6802223.96 & 2175.035768 \\
\hline 10 & 2236369 & 0.92873448 & 1,202 & 1.802828619 & 4031790.036 & 1116.338845 \\
\hline 11 & 2063346 & 1.083855543 & 5,313 & 0.226237531 & 466806.3038 & 5758.524502 \\
\hline 12 & 1648745 & 1.251464599 & 1,867 & 2.845741832 & 4691902.616 & 2336.484406 \\
\hline 13 & 2096898 & 0.786278112 & 16,496 & 0.113178952 & 237324.7191 & 12970.44373 \\
\hline 14 & 1691511 & 1.239659689 & 701 & 23.532097 & 39804800.94 & 869.0014419 \\
\hline 15 & 1847580 & 0.91552788 & 299 & 2.344481605 & 4331617.324 & 273.742836 \\
\hline 16 & 1828905 & 1.010211028 & 5,076 & 0.058904649 & 107731.0077 & 5127.831178 \\
\hline 17 & 1901645 & 0.961748907 & 2,990 & 1.697658863 & 3228344.488 & 2875.629232 \\
\hline 18 & 1571001 & 1.210467084 & 3,954 & 0.756196257 & 1187985.076 & 4786.186852 \\
\hline 19 & 1853567 & 0.847555551 & 677 & 5.840472674 & 10825707.41 & 573.795108 \\
\hline 20 & 1951443 & 0.949844295 & 292 & 2.318493151 & 4524407.229 & 277.3545341 \\
\hline 21 & 2199546 & 0.887202632 & 9,720 & 0.030041152 & 66076.8963 & 8623.609581 \\
\hline 22 & 2109323 & 1.04277344 & 9,421 & 1.031737607 & 2176267.865 & 9823.968575 \\
\hline 23 & 2079250 & 1.014463388 & 15,718 & 0.599376511 & 1246253.611 & 15945.33554 \\
\hline 24 & 1367515 & 1.520458642 & 24,650 & 0.637647059 & 871991.9176 & 37479.30553 \\
\hline 25 & 2051319 & 0.666651554 & $(3,947)$ & -6.245249557 & -12810999.08 & -2631.273685 \\
\hline 26 & 2480818 & 0.826872024 & $(6,731)$ & 0.586391324 & 1454730.151 & -5565.675591 \\
\hline 27 & 1229067 & 2.018456276 & 1,354 & -4.971196455 & -6109933.513 & 2732.989798 \\
\hline 28 & 2608108 & 0.471248507 & $(8,903)$ & -0.152083567 & -396650.3686 & -4195.525454 \\
\hline 29 & 2213454 & 1.17829781 & $(7,471)$ & 1.191674475 & 2637716.633 & -8803.062936 \\
\hline 30 & 2367885 & 0.934781039 & $(2,782)$ & 2.685478073 & 6358903.248 & -2600.56085 \\
\hline 31 & 1900368 & 1.24601393 & 2,013 & -1.38201689 & -2626340.674 & 2508.226041 \\
\hline 32 & 2332573 & 0.814708907 & 17,624 & 0.114219246 & 266424.7304 & 14358.42978 \\
\hline 33 & 2665198 & 0.87519689 & 17,578 & 1.002616907 & 2672172.577 & 15384.21093 \\
\hline 34 & 2684588 & 0.99277729 & 1,980 & 8.877777778 & 23833175.69 & 1965.699035 \\
\hline 35 & 2640031 & 1.016877453 & 11,931 & 0.165954237 & 438124.3299 & 12132.3649 \\
\hline 36 & 2125469 & 1.242093392 & 5,278 & 2.260515347 & 4804655.293 & 6555.768923 \\
\hline 37 & 2807444 & 0.757083311 & 19,646 & 0.268655197 & 754234.4208 & 14873.65874 \\
\hline 38 & 2512192 & 1.117527641 & 4,335 & 4.53194925 & 11385126.65 & 4844.482325 \\
\hline 39 & 3155650 & 0.796093356 & $(25,757)$ & -0.168303762 & -531107.7668 & -20504.97658 \\
\hline 40 & 2960672 & 1.065855995 & 862 & -29.88051044 & -88466390.61 & 918.7678676 \\
\hline 41 & 3063147 & 0.966545843 & 1,287 & 0.66977467 & 2051618.27 & 1243.9445 \\
\hline 42 & 2790268 & 1.097796699 & 1,726 & 0.745654693 & 2080576.429 & 1894.797103 \\
\hline 43 & 2830172 & 0.985900504 & 2,000 & 0.863 & 2442438.436 & 1971.801007 \\
\hline 44 & 2883472 & 0.98151534 & 3,609 & 0.55417013 & 1597934.054 & 3542.288861 \\
\hline 45 & 2986076 & 0.965639187 & 4,546 & 0.793884734 & 2370600.15 & 4389.795743 \\
\hline 46 & 3245798 & 0.919982081 & 29,160 & 0.155898491 & 506015.0106 & 26826.6775 \\
\hline
\end{tabular}


Appendix 1. Computations of the components of the classical econometric models (continued)

\begin{tabular}{|c|c|c|c|c|c|c|}
\hline \multirow{2}{*}{$\begin{array}{l}\text { Months } \\
\mathrm{T}\end{array}$} & \multirow{2}{*}{$\begin{array}{l}\text { Actual } \\
\text { usage } \\
\mathrm{X}^{-}\end{array}$} & \multirow{2}{*}{$\begin{array}{l}\begin{array}{c}\text { Backshift } \\
\text { operator } \\
\text { Bx }\end{array} \\
\end{array}$} & \multirow[t]{2}{*}{ Loss } & \multicolumn{3}{|c|}{ Backshift operator } \\
\hline & & & & By & Byxt & BxYt \\
\hline 47 & 2571803 & 1.262071006 & 6,197 & 4.705502663 & 12101625.86 & 7821.054026 \\
\hline 48 & 2139536 & 1.202037732 & 1,544 & 4.013601036 & 8587243.907 & 1855.946258 \\
\hline 49 & 3356131 & 0.637500741 & 25,184 & 0.061308767 & 205760.2551 & 16054.81867 \\
\hline 50 & 3302996 & 1.01608691 & 24,186 & 1.041263541 & 3439289.311 & 24575.07801 \\
\hline 51 & 3957446 & 0.834628192 & 3,639 & 6.64633141 & 26302497.65 & 3037.211991 \\
\hline 52 & 3040356 & 1.301639019 & 3,312 & 1.098731884 & 3340536.076 & 4311.02843 \\
\hline 53 & 3579473 & 0.849386488 & 3,956 & 0.837209302 & 2996768.093 & 3360.172946 \\
\hline 54 & 3815179 & 0.938218888 & 5,155 & 0.767410281 & 2927807.59 & 4836.518369 \\
\hline 55 & 2957342 & 1.290070273 & 3,296 & 1.56401699 & 4625333.134 & 4252.071618 \\
\hline 56 & 3861317 & 0.765889462 & $(6,613)$ & -0.498412218 & -1924527.572 & -5064.827013 \\
\hline 57 & 3628468 & 1.064172813 & 1,388 & -4.764409222 & -17287506.4 & 1477.071865 \\
\hline 58 & 3877466 & 0.935783318 & 2,270 & 0.611453744 & 2370891.105 & 2124.228132 \\
\hline 59 & 3084324 & 1.257152621 & 4,484 & 0.506244425 & 1561421.829 & 5637.072352 \\
\hline 60 & 3003163 & 1.027025173 & 3,776 & 1.1875 & 3566256.063 & 3878.047054 \\
\hline
\end{tabular}

